\title{
The influence of the intrauterine environment on human placental development
}

\author{
GRAHAM J. BURTON*,1, ERIC JAUNIAUX² and D. STEPHEN CHARNOCK-JONES ${ }^{1}$ \\ ${ }^{1}$ Centre for Trophoblast Research, University of Cambridge, Cambridge and \\ ${ }^{2}$ Academic Department of Obstetrics and Gynaecology, Royal Free and University College, London, UK
}

\begin{abstract}
Development of the human placenta is modulated heavily by the intrauterine environment. During the first trimester, development takes place in a low oxygen environment supported by histiotrophic nutrition from the endometrial glands. Consequently, the rate of growth of the chorionic sac is almost invariable across this period, and is remarkably uniform between individuals. Towards the end of the first trimester the intrauterine environment undergoes radical transformation in association with onset of the maternal arterial circulation and the switch to haemotrophic nutrition. The accompanying rise in intraplacental oxygen concentration poses a major challenge to placental tissues, and extensive villous remodelling takes place at this time. Later in pregnancy a wide variety of stressors are capable of affecting placental growth, but in the human, the most common are nutrient deprivation and vascular compromise. The latter is usually secondary to deficient trophoblast invasion and can induce placental oxidative stress. Closely linked to oxidative stress is endoplasmic reticulum stress, and we recently provided the first evidence that the latter plays a major role in the pathophysiology of intrauterine growth restriction. The endoplasmic reticulum is a key regulator of protein synthesis, exerting its effects through the unfolded protein response. Consequently, we observed multiple blocks to translation initiation and elongation in growth restricted placentas. Nutrient deprivation also modulates protein synthesis through the mTOR pathway, and we demonstrated interactions between this pathway and endoplasmic reticulum stress. Protein synthesis inhibition therefore appears to be a common mechanism for regulating placental development under different adverse conditions.
\end{abstract}

KEY WORDS: placenta, oxidative stress, protein synthesis, growth restriction, endoplasmic reticulum stress

\section{Introduction}

It is axiomatic that normal development of the placenta is an essential prerequisite for growth of a healthy fetus. This has been confirmed by both longitudinal studies in the human and experimental manipulations in animals demonstrating that deficient placental growth precedes growth restriction of the fetus. Classic experiments, such as the Shire horse-Shetland pony crosses conducted by Walton and Hammond (1938), have shown that the intrauterine environment exerts a powerful influence over placental development. Recent research has shown that in the human the intrauterine environment changes radically between the first trimester and the remainder of pregnancy due to a switch from histiotrophic to haemotrophic nutrition with onset of the maternal arterial circulation to the placenta. Adapting to the new conditions poses a major challenge to the placental tissues, and extensive remodelling takes place at that time. Later in pregnancy, vascular or dietary compromise can limit placental growth through their effects on protein synthesis. In this review, we consider the molecular mechanisms by which these effects are mediated, and identify common pathways.

\section{The first trimester}

In normal human pregnancies the rate of growth of the embryo and of the chorionic sac during the first trimester is remarkably constant between individuals (Blaas et al., 1998), suggesting that once started early growth is autonomous and that it occurs under

Abbreviations used in this paper: IHC, immunohistochemistry; mTOR, mammalian target of rapamycin.

\footnotetext{
*Address correspondence to: Graham J. Burton. Physiological Laboratory, Downing Street, Cambridge CB2 3EG. UK. Fax: +44-1223-333-840. e-mail: gjb2@cam.ac.uk
} 

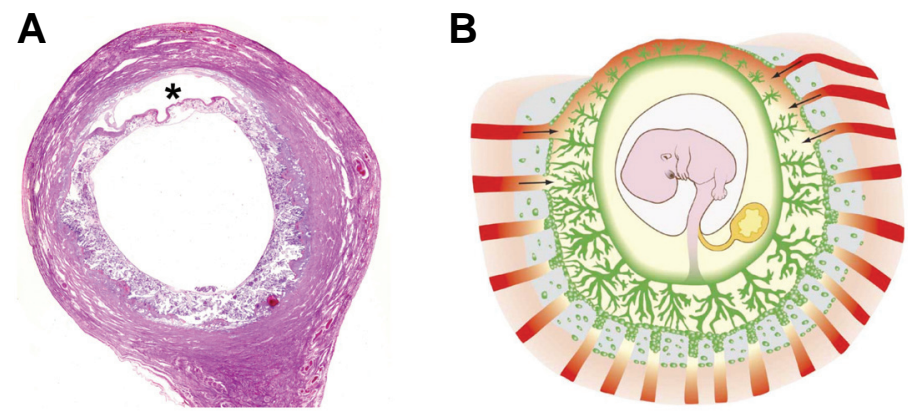

Fig. 1. Formation of the chorion laeve. (A) A placenta-in-situ specimen at 8.5 weeks of gestational age illustrating regression of the villi over the superficial pole of the chorionic sac (asterisk). (B) Diagrammatic representation of how onset of the maternal arterial circulation in the periphery of the placenta (arrows), where cytotrophoblast plugging of the spiral arteries is minimal, causes a localised increase in oxidative stress (depicted by the red shading) in the villi over the superficial pole. This is believed to induce regression of the villi, giving rise to the chorion laeve. Adapted from (Jauniaux et al., 2003b) with permission from the American Society for Investigative Pathology and (Jauniaux et al., 2004) with permission from The Endocrine Society respectively.

stable conditions. During this period the conceptus is supported by secretions from the endometrial glands delivered into the placenta through the developing basal plate (Burton et al., 2002). This relationship might be best described as 'deciduochorial' to distinguish it from the more familiar haemochorial state that exists during the second and third trimesters. Hormonal manipulation of endometrial gland morphogenesis in the sheep has confirmed the importance of these secretions for normal development of the conceptus (Gray et al., 2001). In this species, and in the pig and rabbit, the conceptus influences the secretory activity of the glands via a series of endocrine and paracrine signals (Spencer et al., 2004). In contrast, little is known regarding the composition of the secretions in the human, although it is clear from histochemical staining that they are carbohydrate-rich and contain numerous lipid droplets. In addition, a wide variety of cytokines and growth factors are present, such as epidermal growth factor, vascular endothelial growth factor and transforming growth factor beta, and receptors for all these are present on the villous tissues. Hence, the secretions have the potential to play an important role in regulating placental cell proliferation and differentiation in the early stages of pregnancy (Hempstock et al., 2004; Burton et al., 2007b).

The reliance on histiotrophic nutrition during the phase of organogenesis is common to many mammalian species. The principal benefit would appear to be that the oxygen concentration within the chorionic sac is maintained at a relatively low value, and this may protect from teratogenesis mediated by reactive oxygen species (Burton et al., 2003; Jauniaux et al., 2003a). Free radicals, molecules possessing unpaired electrons, are highly reactive and may interfere with development by direct attack on genomic DNA or by causing misfolding and inactivation of intermediate signalling molecules. A rise in the prevailing oxygen concentration, or a reduction in antioxidant defences, is associated with greater oxidative damage to embryonic DNA, and an increased risk of both major and minor congenital abnormalities (Eriksson, 1999; Nicol et al., 2000; Ornoy, 2007). Maintaining metabolism at a low level during blastocyst development improves pregnancy outcome (Leese,
2002), and it would appear that the same may apply during the phase of organogenesis. Experimental data also suggest that a low oxygen environment is necessary to maintain human embryonic stem cells in a pluriopotent state (Ezashi et al., 2005), and for promoting proliferation of cytotrophoblast cells, both in vitroand in vivo (Fox, 1964; Genbacev et al., 1996; Ali, 1997). Daughter cells may then feed through into either the villous or extravillous trophoblast population.

\section{Onset of the maternal arterial circulation to the placenta}

Under these protective conditions the early placenta develops rapidly, and so by the end of the third week post-conception villi surround the whole of the chorionic sac. Initially, the villi are almost uniform in length, but later those over the superficial pole begin to regress (Fig. 1A). The cause for this has long been unknown, but we recently speculated that it is driven by oxidative stress arising from onset of the maternal arterial circulation to the placenta (Fig. 1B). During the first trimester the placental intervillous space is filled with a clear fluid (Schaaps and Hustin 1988), for maternal erythrocytes are prevented from entering by the presence of endovascular trophoblast plugs that occlude the tips of the spiral arteries (Hustin and Schaaps 1987; Burton et al., 1999). These plugs are a component of the general phenomenon of extravillous trophoblast invasion that occurs during the first and second trimesters of human pregnancy (Pijnenborg et al., 2006). The extent of this invasion varies across the placental bed, being greatest in the central region and least in the periphery (Pijnenborg et al., 1981). Intriguingly, when the maternal arterial circulation is first established ultrasound evidence of significant flow is more often observed in the peripheral regions of the placenta than in the centre under the insertion of the umbilical cord (Jauniaux et al., 2003b). This may reflect incomplete plugging of the arteries in the periphery due to the less extensive trophoblast invasion (Pijnenborg et al., 1981).

Onset of the maternal arterial circulation leads to a three-fold rise in the intraplacental oxygen concentration (Rodesch et al., 1992; Jauniaux et al., 2000). This poses a major challenge to the placental tissues, as it will result in increased production of potentially damaging reactive oxygen species from mitochondria and other sources. The syncytiotrophoblast layer is particularly vulnerable as it contains low concentrations of the principal antioxidant enzymes during early pregnancy (Watson et al., 1997; Watson et al., 1998). Consequently, exposure of first trimester villi to ambient concentrations of oxygen in vitro results in rapid degeneration of the syncytiotrophoblast (Palmer et al., 1997), although the cytotrophoblast and stromal cells survive in short-term culture. Morphologically similar, but less severe, changes are observed in the peripheral region of the placenta, where they are associated with an increase in markers of oxidative stress such as nitrosylation of tyrosine residues, expression of heat shock proteins and increased lipid peroxidation (Fig. 2 A,B and Table 1) (Jauniaux et al., 2003b). We also observe increased activation of the apoptotic cascade by Western blotting in samples from the peripheral region of the placenta, and immunohistochemistry localised this principally to the cytotrophoblast cells (Fig. 2 C,D). Equally, proliferation, as identified by immunostaining with antibodies directed against Ki67 is lower in the peripheral villi. It would seem reasonable to conclude that this combination of increased cell death and decreased renewal will ultimately lead to regression of the villi. Indeed, in 
TABLE 1

\section{SUMMARY OF THE PRINCIPAL DIFFERENCES OBSERVED BETWEEN CENTRAL AND PERIPHERAL VILLI IN PLACENTAS OF 8-12 WEEKS GESTATIONAL AGE*}

\begin{tabular}{|c|c|c|}
\hline Observation & Centre & Periphery \\
\hline Maternal blood flow & rare before $12-13$ weeks & common at 8-9 weeks \\
\hline Syncytiotrophoblast layer & thick with profuse microvilli & thin with few microvilli \\
\hline Syncytiotrophoblast mitochondria & parallel cristae with narrow intracristal spaces & distorted cristae with dilated intracristal spaces \\
\hline Cytotrophoblast cells & numerous, rounded and undifferentiated & fewer, elongated and more differerntiated \\
\hline Villous vasculature & central and peripheral villous capillaries & degenerating capillaries and many avascular villi \\
\hline Stromal cells & numerous & few \\
\hline IHC reactivity for nitrotyrosine residues & weak & strong, especially in the syncytiotrophoblast \\
\hline IHC reactivity for lipidperoxidation & weak & strong, especially in the syncytiotrophoblast \\
\hline IHC reactivity for inducible heat shock protein 70 & weak & strong, especially before 11 weeks \\
\hline IHC for Ki67 & scattered cytotrophoblast cells & reduced compared to centre \\
\hline Western blotting for active caspases 3 and 9 & weak & strong \\
\hline
\end{tabular}

*Data collated mainly from Jauniaux et al. (2003b)

placenta-in-situspecimens it appears that the villi over the superficial pole of the chorionic sac are reduced to little more than hypocellular cores of collagen and other extracellular fibres covered by a severely attenuated layer of trophoblast (Jauniaux et al., 2003b) (Fig. 2 E,F). In this way the chorion frondosum is transformed into the smooth chorion, the chorion laeve, and the definitive placenta.

This suggested mechanism of chorionic villous regression to form the discoid placenta is supported by findings from cases of missed miscarriage. In these onset of the maternal arterial circulation is precocious, and occurs in a disorganised fashion throughout the placenta. In two-thirds of cases this is secondary to shallow trophoblast invasion (Khong et al., 1987; Hustin et al., 1990), which will lead to incomplete plugging of the spiral arteries. Villi that are maintained in this physiologically hyperoxic environment show increased levels of oxidative stress and equivalent morphological changes to those in the periphery of the normal placenta (Jauniaux etal., 1994a; Jauniaux etal., 2003b). As time progresses after the onset of the blood flow the fetal capillaries involute, leaving only avascular hypocellular villous ghosts. On ultrasound the thickness of the placenta is seen to gradually decrease until only a thin shell persists. The regression of villi that occurs during formation of the chorion laeve and in cases of missed miscarriage may therefore be considered physiological and pathological manifestations of the same oxygen-induced phenomenon.

\section{Abnormal placental shapes}

Placentas display a wide range of shapes across

Fig. 2. Comparison of villi from the central and peripheral regions of the first trimster placenta. (A-D) Villi removed from the centre and periphery of a 10 week gestational age placenta immunostained against hydroxynonenal (HNE) to detect lipid peroxidation, and active (cleaved) caspase 3 to detect apoptosis. Villi from the periphery react more strongly for both, particularly in the synctyotrophoblast and cytotrophoblast layers. (E,F) Villi from the central and peripheral regions of the placenta-in-situ specimen shown in Fig. 1 illustrating how the regressing villi are hypocellular, avascular and have a very thin trophoblast covering. mammalian species, being diffuse in the pig, cotyledonary in the ruminants, zonary in many carnivores and discoid in the rodents and primates (Mossman, 1987). In almost all cases this is due to differential outgrowth of villi from the chorionic sac, often opposite specialised areas of the endometrial surface. The situation depicted above where villi regress to leave a discoid placenta appears to be unique to the human and the great apes, and is presumably related to the phenomenon of interstitial implantation.

Although the human placenta is classified as being discoid, in reality the margins are often irregular and do not conform to a circular profile. In these cases the insertion of the umbilical cord
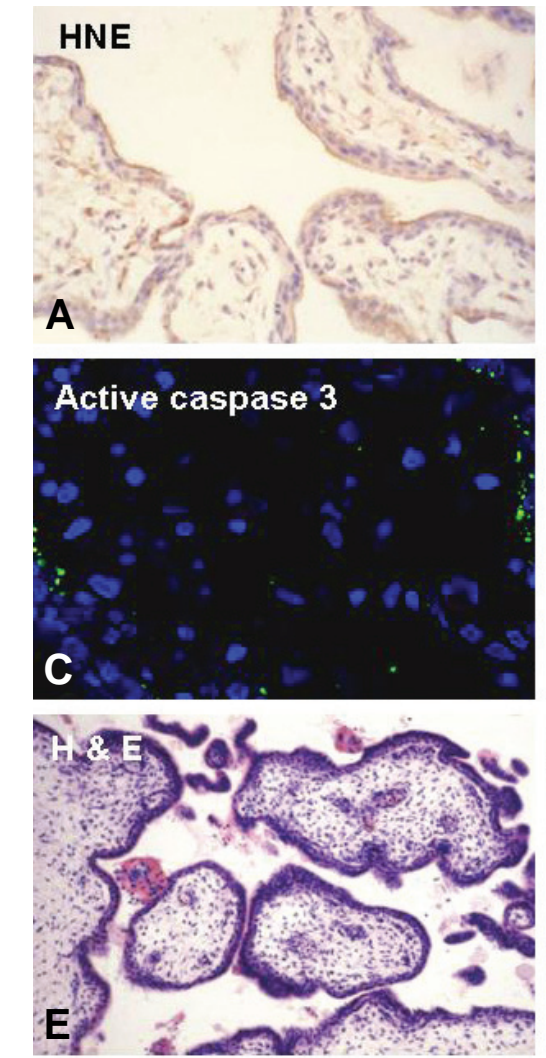

Centre
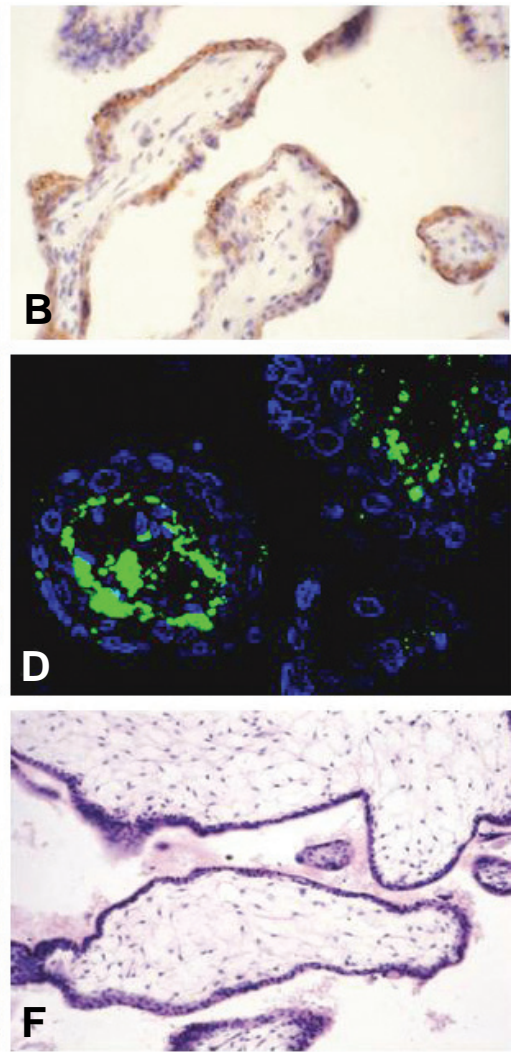

Periphery 
can be highly eccentric. Such placentas are found more commonly in pregnancies resulting from in-vitro-fertilization and embryo transfer, and in multiple pregnancies (Jauniaux et al., 1990; Gavriil et al., 1993). Overall, they are often associated with a poorer obstetric outcome (Salafia et al., 2005; Toal et al., 2007). The realisation that regression is associated with oxidative stress and onset of the maternal arterial blood flow to the placenta enables us to link these findings through abnormal trophoblast invasion and incomplete physiological conversion of the spiral arteries. Physiological conversion is essential for ensuring an adequate blood flow to the placenta in later gestation, and complications such as intrauterine growth restriction and preeclampsia are associated with defects in this process (Brosens et al., 1977; Gerretsen et al., 1981). Conversion leads to dilation of the distal segments of the arteries, reducing the rate and the pressure with which the maternal blood enters the intervillous space. It also removes the highly contractile segment of the artery lying at the endometrial-myometrial boundary, and we have suggested that this ensures greater constancy of placental perfusion (Burton et al., 2009). Although the molecular mechanisms are still unknown, conversion is dependent in the human on the presence of both interstitial and endovascular extravillous trophoblast (Kam et al., 1999; Pijnenborg et al., 2006). There is quantitative evidence that the number of these cells is reduced in complicated pregnancies (Naicker et al., 2003). Because it is the endovascular trophoblast migrating down the lumen that plugs the arteries during the first trimester it is not unreasonable to assume that incomplete conversion of the arteries may also be associated with poor plugging of the vessels, and so early onset of the maternal blood flow.

The factors regulating trophoblast invasion are not fully under-

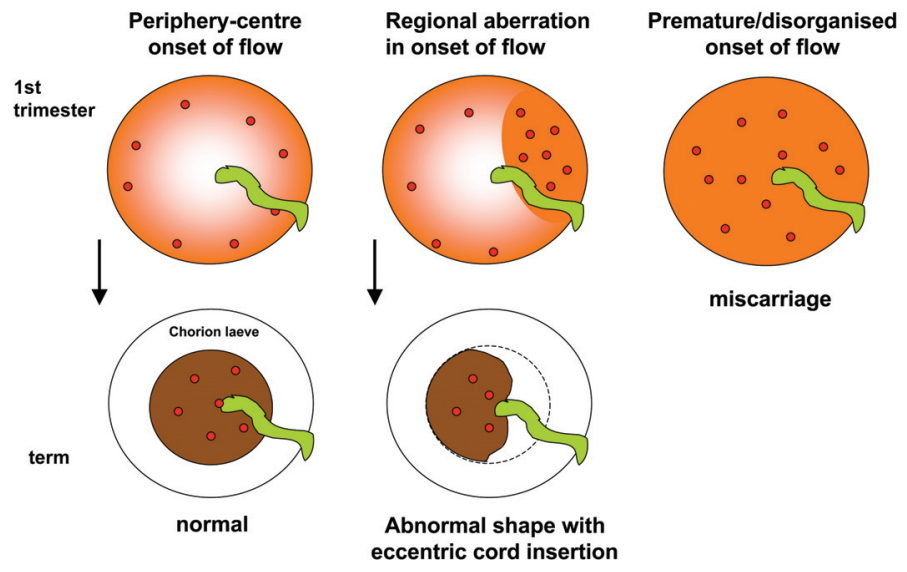

Fig. 3. Diagrammatic representation of villous regression associated with onset of the maternal arterial circulation (small red circles) to the placenta in normal and abnormal pregnancies. In normal pregnancies flow starts in the periphery of the placenta and local oxidative stress, depicted by red shading, leads to villous regression and formation of the chorion laeve, shown in white. In cases of miscarriage onset of the circulation occurs precociously and throughout the placental disc, leading to overwhelming oxidative stress and pregnancy loss. An intermediate state may occur if trophoblast invasion is particularly shallow in an area of the placental bed. Early onset of flow in that region will cause excessive villous regression, leading to abnormal placental shape and eccentric cord insertion.

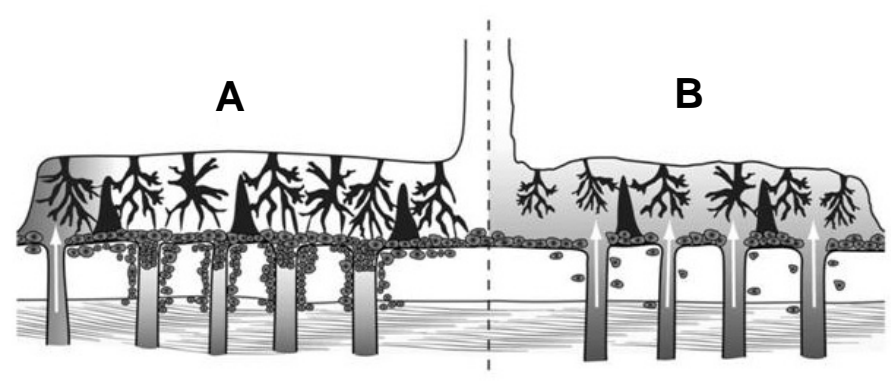

Fig. 4. Diagrammatic representation of trophoblast invasion in normal (A) and abnormal (B) pregnancies. In abnormal pregnancies shallow invasion results in deficient plugging of the spiral arteries and early onset of the maternal intraplacental circulation. The force of the jetlike spurts of maternal blood damages the developing villi, rupturing the cytotrophoblast cell columns of the anchoring villi. As a result the placenta may be thicker than normal, and have an abnormal texture with the presence of villus-free placental lakes. Reproduced from Johns et al., 2006) with permission.

stood, but it is highly likely that the local endometrial environment, including cells of the maternal immune system, plays a key role. Thus, the extent of spiral arterial conversion is variable across the normal placental bed, and even between different segments of the same vessel (Pijnenborg et al., 1981; Meekins et al., 1994). In pregnancies where trophoblast invasion is compromised, particularly shallow invasion in areas of the placental bed could lead to the early onset of the circulation normally seen in the periphery extending into the central region. As a result excessive villous regression will occur, the placental shape will be abnormal, and the cord insertion eccentric (Fig. 3). The remaining spiral arteries in the placental bed may not be fully converted, and as a result maternal blood enters the intervillous space at excessive velocity. The haemodynamics of the maternal circulation to the placenta play an important role in shaping the topography of the villous trees. Villi in the early placenta initially form a uniform dense meshwork, but once the spiral arteries open towards the end of the first trimester they become organised into the lobular arrangement, with villus-free central cavities forming over the arterial openings in the basal plate (Reynolds et al., 1968). In an equivalent fashion, villus-free placental lakes are formed by the jet-like inflow of blood from non-converted arteries. The force of this inflow may also rupture the cell columns of the anchoring villi, resulting in the placenta becoming thicker or more globular than normal. This combination of changes affects the placental texture, rendering it 'jelly-like' and more 'wobbly' (Jauniaux et al., 1994b, Jauniaux and Nicolaides, 1996, Toal et al., 2007) (Fig. 4). These placentas are often associated with intrauterine growth restriction. This may reflect excessive loss of villous tissue at the time of onset of the circulation, but may also be due to impoverished growth during the second and third trimesters due to chronic oxidative and other stresses induced through malperfusion of the organ.

\section{Placental growth during the second and third trimes- ters}

The application of ultrasound imaging to obstetric practice in the 1950s enabled the placenta to be visualised in vivofor the first time in a safe and reproducible fashion. Longitudinal studies have 
revealed that placental development follows different trajectories in normal and complicated pregnancies, and that these differences are established at the end of the first trimester. Thus in cases of intrauterine growth restriction the placenta is smaller than normal at 12 weeks but grows at the same rate thereafter. If there is accompanying preeclampsia, however, the subsequent rate of growth is slowed (Hafner et al., 2003). In cases of lateonset preeclampsia placental size is often increased at 12 weeks, but then the rate of growth slows between 16 and 20 weeks. The importance of these trajectories in the causation of fetal growth restriction is highlighted by the finding that fetal anthropometric measurements are positively correlated with placental volume at 14 weeks and with the rate of placental growth between 17 and 20 weeks (Thame et al., 2004).

There are many potential non-genetic causes of intrauterine growth restriction. On a world-wide basis maternal malnutrition is still one of the principal reasons, but in developed countries it is more usually the result of utero-placental malperfusion secondary to incomplete spiral artery conversion (Brosens et al., 1977; Gerretsen et al., 1981). Infection, metabolic disorders and endocrine disturbances can also be causative, and in experimental animals growth restriction can be induced by heat stress, uterine artery ligation or surgical reduction of the placental area (see Fowden et al., 2008 for recent review). Recent advances are now shedding light on the common molecular mechanisms by which a variety of stressors can influence the rate of growth of cells and tissues (Patel et al., 2002; Proud, 2007). Regulation of the cellular protein synthetic machinery lies at the centre of this complex network (Fig. 5), for without an adequate rate of protein synthesis cells cannot enlarge sufficiently to be able to divide.

\section{Regulation of the protein synthetic machinery}

Protein synthesis demands a high energy supply, and estimates suggest it accounts for approximately 30\% of human placental oxygen consumption (Carter, 2000). Indeed, placental oxygen consumption is high compared to other tissues, reflecting its considerable secretory and active transport functions. Thus, when the supply of oxygen is reduced, either through vascular compromise or exposure to hypobaric hypoxia at altitude, one might expect the placenta to conserve energy by shutting down its protein synthetic machinery. Equally, preventing protein translation in an infected cell is an effective host defence against the establishment and spread of disease. Protein synthesis comprises three main stages; initiation, elongation and termination or release. Each step is subject to a number of regulatory mechanisms that are controlled by families of factors referred to in eukaryotes as elFs, eEFs and eRFs respectively. Of the three stages, translation initiation is subject to the greatest degree of control and can respond rapidly to changes in the cellular environment.

Regulatory phosphorylation of a member of the elF family, elF2 $\alpha$, plays a key role in these responses. Translation is initiated by the binding of elF4E to the 5' cap of the mRNA, which in turn leads to binding of other regulatory subunits and the recruitment of the $40 \mathrm{~S}$ subunit of the ribosome. This complex scans along the 5' UTR to locate the start codon. The methionyl initiator tRNA is brought to the ribosome by another factor, elF2, which is a GTPbinding protein. During translation initiation the GTP is hydrolysed, and elF2-GTP needs to be regenerated for the process to continue. This requires elF2B, a guanine-nucleotide-exchangefactor, which is competitively inhibited by P-elF2 $\alpha$. Hence, phosphorylation of elF2 $\alpha$ blocks recycling and protein translation (Fig. $6)$.

Four serine/threonine protein kinases have been identified that can phosphorylate elF2 $\alpha$; GCN2 which is activated by uncharged tRNAs and so is sensitive to amino acid depletion, the haemregulated inhibitor $\mathrm{HRI}$ which is responsive to hypoxia, the doublestranded RNA-activated kinase PKR which is responsive to viral infections, and PERK which is localised to the lumen of endoplasmic reticulum and activated by the accumulation of misfolded proteins (Wek et al., 2006). In this way cells are able to modulate the rate of protein synthesis rapidly to accommodate to a variety of unfavourable stresses.

We have recently identified increased levels of phosphorylation of elF2 $\alpha$ in non-laboured placentas from cases of intrauterine growth restriction with a uterine vascular aetiology compared to normal controls, and to an even greater degree in cases associated with early-onset preeclampsia (Yung et al., 2008). We also observed activation of PERK and both morphological and molecular evidence of endoplasmic reticulum stress, suggesting a causal link. In support of that linkage, we have demonstrated that the induction of endoplasmic reticulum stress in trophoblast-like cell lines by ischaemia-reperfusion or tunicamycin results in a major suppression of protein synthesis (Yung et al., 2007), including translation of kinases such as AKT that play a central role in cell proliferation. As a result the cells proliferate at a slower rate, which in vivo would lead to the growth restricted placental phenotype. In other cell systems it has been shown that levels of cyclin D1 are reduced through translation inhibition secondary to induction of endoplasmic reticulum stress (Brewer et al., 1999). We observed a similar reduction in cyclin D1 in our growth restricted placentas (Yung et al., 2008).

\section{Placental endoplasmic reticulum and oxidative stress}

The cause of the endoplasmic reticulum stress in these placentas is not proven, but it is highly likely to be secondary to maternal

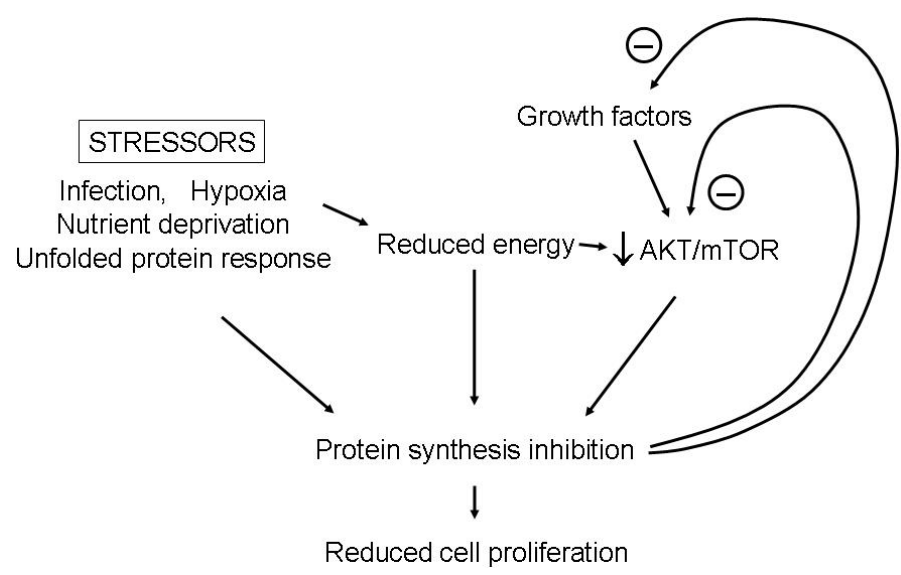

Fig. 5. Overview diagram of how various stressors can reduce the rate of cell proliferation through inhibition of protein synthesis. Several feed-forward systems can operate to make the situation worse. For example, levels of autocrine growth factors and kinases of the AKTI mTOR pathway may be reduced due to the blocks to translation, further inhibiting protein synthesis. 
malperfusion. There is no doubt that the preeclamptic placenta displays considerable evidence of oxidative stress (Hubel, 1999; Myatt and Cui, 2004), and it is generally assumed that the same holds in cases of intrauterine growth restriction alone. We recently proposed that the retention of smooth muscle within the walls of the incompletely converted spiral arteries renders them liable to spontaneous vasoconstriction, leading to fluctuations in intraplacental oxygen concentrations. Experiments in vitro have confirmed that hypoxia-reoxygenation is a powerful inducer of oxidative stress, and that the pattern of stress markers, such as nitrosylation of tyrosine residues, closely matches that seen in preeclamptic placentas (Myatt et al., 1996; Hung et al., 2001). Further support is provided by the observation that placentas subjected to labour, when perfusion is interrupted intermittently by the uterine contractions, display higher levels of oxidative stress than non-laboured controls. Furthermore, changes in the gene transcript profile closely resemble those seen in preeclampsia (Cindrova-Davies et al., 2007b).

In other situations there is a close link between oxidative stress, endoplasmic reticulum stress and ischaemia-reperfusion injury (DeGracia and Montie, 2004; Cullinan and Diehl, 2006). Both depletion of ATP and increased generation of reactive oxygen species can cause the release of calcium from the endoplasmic reticulum through the inhibition of ATP-dependent ion pumps. Depletion of calcium within the lumen results in loss of function of $\mathrm{Ca}^{2+}$-dependent chaperone proteins, such as GRP78, resulting in protein misfolding and activation of the unfolded protein response. One arm of that response aims to inhibit the introduction of new proteins into the lumen of the endoplasmic reticulum, and this is achieved through the action of PERK on elF $2 \alpha$.

\section{The mTOR pathway as a central regulator of translational control}

Phosphorylation of elF $2 \alpha$ by PERK, or one of the other three kinases, provides for rapid control of translation initiation, but other stages of protein synthesis can also be regulated through mTOR (mammalian target of rapamycin), a multidomain protein that displays protein kinase activity (Proud, 2007). mTOR functions to integrate extracellular signals from growth factors and hormones with amino acid availability, intracellular energy status and protein synthesis (Fingar and Blenis, 2004; Hay and Sonenberg, 2004; Jansson and Powell, 2006). For example, it is capable of regulating cap-dependent translation initiation by controlling the binding of elF4E to the mRNA. This control is exerted through phosphorylation of a binding protein, 4E-BP1, that in its unphosphorylated state associates with elF4E and prevents its interaction with the mRNA. We observed reduced phosphorylation of 4E-BP1 in our growth restricted placentas (Yung et al., 2008), indicating a second block to protein translation and suggesting activity of the mTOR pathway is reduced in these cases (Fig. 6).

mTOR is regulated through the intermediate Rheb by the dimeric TSC1/2 (tuberous sclerosis) complex, which in turn is subject to regulatory phosphorylation by both AKT and AMPK. AKT is activated by a variety of cytokines and growth factors through the PI3-kinase pathway, and stimulates mTOR through its actions on TSC1/2 (Yang et al., 2004). AKT can also phosphorylate mTOR directly, although the importance of this is contentious (Sekulic et al., 2000). AMPK on the other hand is activated by the accumulation of AMP and hence detects energy depletion. Its actions are inhibitory to mTOR, suppressing protein synthesis (Fig. 6).

There are three isoforms of AKT, each encoded by a separate gene; AKT1, AKT2 and AKT3. We observed that the protein level of each isoform was dramatically reduced in the growth restricted placentas (Yung et al., 2008). The mRNA levels were unchanged, however, indicating that these kinases were themselves affected by the general protein synthesis inhibition observed in these placentas. A feed-forward cycle may therefore be established, possibly initiated by phosphorylation of elF2 $\alpha$ but leading to reduced activity in the AKT/mTOR pathway (Fig. 5). Genetic knockout of Akt1 in the mouse results in placental and fetal growth retardation (Yang et al., 2003), and we observed a strong correlation between levels of P-Akt and placental weight in both mutant and wild type mice.

Other adverse feed-forward cycles affecting the mTOR pathway may also occur as a result of the translation inhibition observed. Thus, IGF2 protein level was reduced by approximately $70 \%$, suggesting that autocrine signalling is severely compromised, and this was reflected by a reduction in phosphorylation of PDK1, accompanied by a fall in total PDK1 in the growth restricted placentas (Yung $\mathrm{H}-\mathrm{W}$, unpublished data). IGF2 is one of the principal autocrine growth factors secreted by the placenta. The gene has several promoters, including one in the mouse specific to the trophoblast, the PO promoter. The importance of IGF2 to normal placental development was confirmed by the observation that genetic ablation of the P0 promoter alone results initially in growth restriction of the

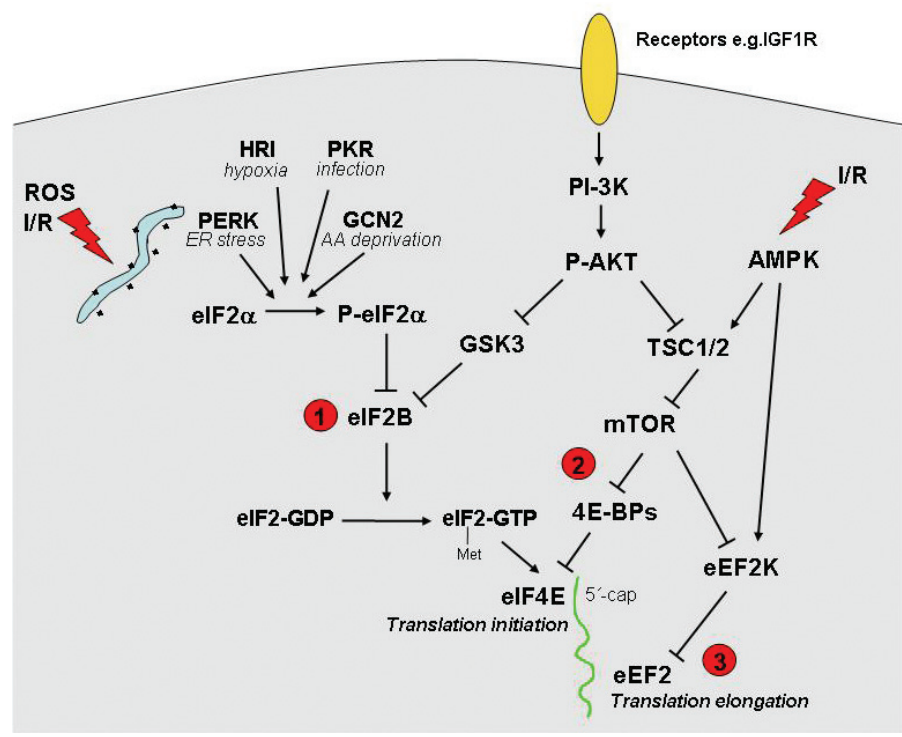

Fig. 6. A diagrammatic representation of the principal molecular mechanisms regulating protein translation initiation and elongation. Initiation may be regulated by blocking the activity of elF4E by preventing the recycling of elF2-GDP (1), or preventing elF4E from binding to the 5'-cap region of the mRNA through the action of binding proteins (2). The elongation phase can be regulated by the action of eEF2 kinase (3). We have observed blocks (1) and (2) to be operative in growth restricted placentas (Yung et al., 2008). 
placenta, which is followed later in pregnancy by growth restriction of the fetus (Constancia et al., 2002).

\section{Other blocks to protein synthesis}

Depletion of AKT can also inhibit translation initiation independent of the mTOR pathway by preventing the recycling of eIF2. As described earlier elF2B is required to regenerate elF2-GTP. One of the subunits of elF2B, epsilon, is subject to regulatory phosphorylation by GSK-3, which in turn is a substrate for AKT. Hence, both P-elF2 $\alpha$ and reduced AKT activity can block initiation (Fig. $6)$.

The elongation phase of protein synthesis involving the eEF2 family is one of the principal sites of regulation by the mTOR pathway, acting through eEF2 kinase. This can also be directly affected by AMPK (Fig. 6). We observed both reduced activation and reduced total level of eEF2K in the growth restricted placentas, suggesting that the elongation phase of protein synthesis may remain active. This may explain why some placental proteins, such as leptin and soluble fms-like tyrosine kinase (sFLT), are markedly increased in preeclampsia and following acute oxidative stress (Levine etal., 2004; Laivuori etal., 2006; CindrovaDavies et al., 2007a). The associated rise in their mRNAs suggests a combination of both transcriptional and translational activation (Tsatsaris et al., 2003; Laivuori et al., 2006). It has been reported that mRNAs containing small upstream open reading frames within their promoter regions or internal ribosome entry sites are selectively translated independent of elF-2 $\alpha$ regulation (Harding et al., 2000; Lu et al., 2004). To date, there are no published reports of these sequences within the promoter regions of the leptin and SFLT genes. However, we found three in-frame upstream open reading frames in the 5'UTR of the leptin mRNA, and consensus motifs for internal ribosome entry sites in the 5'UTR of sFLT1 mRNA (Yung H-W, unpublished data). These observations suggest potential bypass mechanisms exist in both the leptin and sFLT1 promoters that allow their mRNAs to be translated even when initiation is inhibited by P-elF2 $\alpha$. Further promoter analysis is required to confirm these findings.

\section{Overview}

There is no doubt that placental development is influenced heavily by the intrauterine environment. Previously, in the human this has been considered relatively stable throughout pregnancy, but the realisation that the maternal arterial circulation to the placenta is not fully established until the end of the first trimester has led to a radical revision of our understanding. The accompanying rise in oxygenation poses a major challenge to the placental tissues, and temporo-spatial differences in the opening of the spiral arteries are now considered to be a key factor in promoting villous regression and formation of the chorion laeve. Later in pregnancy, a variety of insults, including oxygen and nutrient deprivation, can result in growth restriction. Protein synthesis inhibition provides a common mechanism by which these can act, although there are many potential pathways involved with considerable interconnections. We have recently identified placental endoplasmic reticulum stress as a key step in the pathophysiology of unexplained intrauterine growth restriction, and speculate that this arises secondary to malperfusion. Poor trophoblast invasion leading to deficient plugging and physiological conver- sion of the spiral arteries provides a common link between abnormal villous regression at the end of the first trimester and impoverished growth of the placenta in the second and third trimesters. Understanding the factors regulating trophoblast invasion and the molecular mechanisms underlying physiological conversion remains one of the major challenges for contemporary placentology.

\section{Acknowledgments}

The authors are most grateful to Drs Tereza Cindrova-Davies and Hong-Wa Yung, and to all their collaborators for their input into these studies. The work has been supported by the Wellcome Trust, the Medical Research Council, WellBeing and Tommy's, the baby charity.

\section{References}

ALI, K.Z.M. (1997). Stereological study of the effect of altitude on the trophoblast cell populations of human term placental villi. Placenta 18: 447-450.

BLAAS, H.G., EIK-NES, S.H. and BREMNES, J.B. (1998). The growth of the human embryo. A longitudinal biometric assessment from 7 to 12 weeks of gestation. Ultrasound. Obstet. Gynecol. 12: 346-354.

BREWER, J.W., HENDERSHOT, L.M., SHERR, C.J. and DIEHL, J.A. (1999). Mammalian unfolded protein response inhibits cyclin D1 translation and cellcycle progression. Proc. Natl. Acad. Sci. USA 96: 8505-8510.

BROSENS, I., DIXON, H.G. and ROBERTSON, W.B. (1977). Fetal growth retardation and the arteries of the placental bed. Br. J. Obstet. Gynaecol. 84: 656-663.

BURTON, G.J., HEMPSTOCK, J. and JAUNIAUX, E. (2003). Oxygen, early embryonic metabolism and free radical-mediated embryopathies. Reprod. BioMed. Online 6: 84-96.

BURTON, G.J., WOODS, A.W., JAUNIAUX, E. and KINGDOM, J.C.P. (2009) Rheologocal and physiological consequences of conversion of the maternal spiral arteries for uteroplacental blood flow during human pregnancy. Placenta 30: $473-482$

BURTON, G.J., JAUNIAUX, E. and CHARNOCK-JONES, D.S. (2007). Human early placental development: potential roles of the endometrial glands. Placenta, 28 Supp/ A: S64-69.

BURTON, G.J., JAUNIAUX, E. and WATSON, A.L. (1999). Maternal arterial connections to the placental intervillous space during the first trimester of human pregnancy; the Boyd Collection revisited. Am. J. Obstet. Gynecol. 181: 718-724.

BURTON, G.J., WATSON, A.L., HEMPSTOCK, J., SKEPPER, J.N. and JAUNIAUX, E. (2002). Uterine glands provide histiotrophic nutrition for the human fetus during the first trimester of pregnancy. J. Clin. Endocrinol. Metab. 87: 29542959.

CARTER, A.M. (2000). Placental oxygen consumption. Part I: in vivo studies-a review. Placenta 21 Supp/ A: S31-37.

CINDROVA-DAVIES, T., SPASIC-BOSKOVIC, O., JAUNIAUX, E., CHARNOCKJONES, D.S. and BURTON, G.J. (2007a). Nuclear factor-kappa B, p38, and stress-activated protein kinase mitogen-activated protein kinase signaling pathways regulate proinflammatory cytokines and apoptosis in human placenta explants in response to oxidative stress: effects of antioxidant vitamins. $A m$. J. Pathol. 170: 1511-1520.

CINDROVA-DAVIES, T., YUNG, H.W., JOHNS, J., SPASIC-BOSKOVIC, O., KOROLCHUK, S., JAUNIAUX, E., BURTON, G.J. and CHARNOCK-JONES, D.S. (2007b). Oxidative Stress, Gene Expression, and Protein Changes Induced in the Human Placenta during Labor. Am. J. Pathol. 171: 1168-1179.

CONSTANCIA, M., HEMBERGER, M., HUGHES, J., DEAN, W., FERGUSON SMITH, A., FUNDELE, R., STEWART, F., KELSEY, G., FOWDEN, A., SIBLEY, C. and REIK, W. (2002). Placental-specific IGF-II is a major modulator of placental and fetal growth. Nature 417: 945-948.

CULLINAN, S.B. and DIEHL, J.A. (2006). Coordination of ER and oxidative stress signaling: the PERK/Nrf2 signaling pathway. Int. J. Biochem. Cel/ Biol. 38: 317332.

DeGRACIA, D.J. and MONTIE, H.L. (2004). Cerebral ischemia and the unfolded 
protein response. JNeurochem 91 : 1-8.

ERIKSSON, U.J. (1999). Oxidative DNA damage and embryo development. Nature Med. 5: 715.

EZASHI, T., DAS, P. and ROBERTS, R.M. (2005). Low O2 tensions and the prevention of differentiation of hES cells. Proc. Natl. Acad. Sci. USA 102: 47834788.

FINGAR, D.C. and BLENIS, J. (2004). Target of rapamycin (TOR): an integrator of nutrient and growth factor signals and coordinator of cell growth and cell cycle progression. Oncogene 23: 3151-3171.

FOWDEN, A.L., FORHEAD, A.J., COAN, P.M. and BURTON, G.J. (2008). The placenta and intrauterine programming. JNeuroendocrino/20: 439-450.

FOX, H. (1964). The villous cytotrophoblast as an index of placental ischaemia. J. Obstet. Gynaecol. Br. Commwth. 71: 885-893.

GAVRIIL, P., JAUNIAUX, E. and LEROY, F. (1993). Pathologic examination of placentas from singleton and twin pregnancies obtained after in vitrofertilization and embryo transfer. Pediatr. Path. 13: 453-462.

GENBACEV, O., JOSLIN, R., DAMSKY, C.H., POLLIOTTI, B.M. and FISHER, S.J. (1996). Hypoxia alters early gestation human cytotrophoblast differentiation/ invasion in vitroand models the placental defects that occur in preeclampsia. $J$. Clin. Invest. 97: 540-550.

GERRETSEN, G., HUISJES, H.J. and ELEMA, J.D. (1981). Morphological changes of the spiral arteries in the placental bed in relation to pre-eclampsia and fetal growth retardation. Br. J. Obstet. Gynaecol. 88: 876-881.

GRAY, C.A., TAYLOR, K.M., RAMSEY, W.S., HILL, J.R., BAZER, F.W., BARTOL, F.F. and SPENCER, T.E. (2001). Endometrial glands are required for preimplantation conceptus elongation and survival. Biol. Reprod. 64: 1608-1613.

HAFNER, E., METZENBAUER, M., HOFINGER, D., MUNKEL, M., GASSNER, R., SCHUCHTER, K., DILLINGER-PALLER, B. and PHILIPP, K. (2003). Placental growth from the first to the second trimester of pregnancy in SGA-foetuses and pre-eclamptic pregnancies compared to normal foetuses. Placenta 24: 336342.

HARDING, H.P., NOVOA, I., ZHANG, Y., ZENG, H., WEK, R., SCHAPIRA, M. and RON, D. (2000). Regulated translation initiation controls stress-induced gene expression in mammalian cells. Mol. Cel/6: 1099-1108.

HAY, N. and SONENBERG, N. (2004). Upstream and downstream of mTOR. Genes Dev. 18: 1926-1945.

HEMPSTOCK, J., CINDROVA-DAVIES, T., JAUNIAUX, E. and BURTON, G.J. (2004). Endometrial glands as a source of nutrients, growth factors and cytokines during the first trimester of human pregnancy; a morphological and immunohistochemical study. Reprod. Biol. Endocrinol. 2: 58.

HUBEL, C.A. (1999). Oxidative stress in the pathogenesis of preeclampsia. Proc. Soc. Exp. Biol. Med. 222: 222-235.

HUNG, T.H., SKEPPER, J.N. and BURTON, G.J. (2001). In vitro ischemiareperfusion injury in term human placenta as a model for oxidative stress in pathological pregnancies. Am. J. Pathol. 159: 1031-1043.

HUSTIN, J., JAUNIAUX, E. and SCHAAPS, J.P. (1990). Histological study of the materno-embryonic interface in spontaneous abortion. Placenta 11: 477-486.

HUSTIN, J. and SCHAAPS, J.P. (1987). Echographic and anatomic studies of the maternotrophoblastic border during the first trimester of pregnancy. $A m . J$. Obstet. Gynecol. 157: 162-168.

JANSSON, T. and POWELL, T.L. (2006). IFPA 2005 Award in Placentology Lecture. Human placental transport in altered fetal growth: does the placenta function as a nutrient sensor? - a review. Placenta, 27 Supp/ A: S91-97.

JAUNIAUX, E.., ENGLERT, Y., VANESSE, M., HIDDEN, M. and WILKIN, P. (1990). Pathologic features of placentas from singleton pregnancies obtained by in vitro fertilization and embryo transfert. Obstet. Gynecol. 76: 61-64.

JAUNIAUX, E., ZAIDI, J., JURKOVIC, D., CAMPBELL, S. and HUSTIN, J. (1994a) Comparison of colour Doppler features and pathologic findings in complicated early pregnancy. Hum. Reprod. 9, 243-247.

JAUNIAUX, E., RAMSAY, B. and CAMPBELL S. (1994b) Ultrasonographic investigation of placental morphologic characteristics and size during the second trimester of pregnancy. Am. J. Obstet. Gynecol. 170:130-137.

JAUNIAUX, E. and NICOLAIDES, K.H. (1996). Placental lakes, absent umbilical artery diastolic flow and poor fetal growth in early pregnancy. Ultrasound Obstet. Gynecol. 7: 141-144.
JAUNIAUX, E., WATSON, A.L., HEMPSTOCK, J., BAO, Y.-P., SKEPPER, J.N. and BURTON, G.J. (2000). Onset of maternal arterial bloodflow and placental oxidative stress; a possible factor in human early pregnancy failure. $\mathrm{Am}$. J. Pathol. 157: 2111-2122.

JAUNIAUX, E., GULBIS, B. and BURTON, G.J. (2003a). The human first trimester gestational sac limits rather than facilitates oxygen transfer to the fetus-a review. Placenta, 24, Suppl. A: S86-93.

JAUNIAUX, E., HEMPSTOCK, J., GREENWOLD, N. and BURTON, G.J. (2003b). Trophoblastic oxidative stress in relation to temporal and regional differences in maternal placental blood flow in normal and abnormal early pregnancies. $\mathrm{Am}$ J. Pathol. 162: 115-125.

JAUNIAUX, E., CINDROVA-DAVIES, T., JOHNS, J., DUNSTER, C., HEMPSTOCK, J., KELLY, F.J. and BURTON, G.J. (2004). Distribution and transfer pathways of antioxidant molecules inside the first trimester human gestational sac. J. Clin. Endocrinol. Metab. 89: 1452-1459.

JOHNS, J., JAUNIAUX, E. and BURTON, G.J. (2006). Factors affecting the early embryonic environment. Rev. Gynaecol. Perinat. Pract. 6: 199-210.

KAM, E.P.Y., GARDNER, L., LOKE, Y.W. and KING, A. (1999). The role of trophoblast in the physiological change in decidual spiral arteries. Hum. Reprod. 14: 2131-2138.

KHONG, T.Y., LIDDELL, H.S. and ROBERTSON, W.B. (1987). Defective haemochorial placentation as a cause of miscarriage. A preliminary study. Brit. J. Obstet. Gynaecol. 94: 649-655.

LAIVUORI, H., GALLAHER, M.J., COLLURA, L., CROMBLEHOLME, W.R., MARKOVIC, N., RAJAKUMAR, A., HUBEL, C.A., ROBERTS, J.M. and POWERS, R.W. (2006). Relationships between maternal plasma leptin, placental leptin mRNA and protein in normal pregnancy, pre-eclampsia and intrauterine growth restriction without pre-eclampsia. Mol. Hum. Reprod. 12: 551-556.

LEESE, H.J. (2002). Quiet please, do not disturb; a hypothesis of embryo metabolism and viability. BioEssays 24: 845-849.

LEVINE, R.J., MAYNARD, S.E., QIAN, C., LIM, K.H., ENGLAND, L.J., YU, K.F., SCHISTERMAN, E.F., THADHANI, R., SACHS, B.P., EPSTEIN, F.H., SIBAI, B.M., SUKHATME, V.P. and KARUMANCHI, S.A. (2004). Circulating angiogenic factors and the risk of preeclampsia. N. Engl. J. Med. 350: 672-683.

LU, P.D., HARDING, H.P. and RON, D. (2004). Translation reinitiation at alternative open reading frames regulates gene expression in an integrated stress response. J. Cell Biol. 167: 27-33.

MEEKINS, J.W., PIJNENBORG, R., HANSSENS, M., MCFADYEN, I.R. and VAN ASSCHE, F.A. (1994). A study of placental bed spiral arteries and trophoblast invasion in normal and severe pre-eclamptic pregnancies. Br. J. Obstet Gynaecol. 101: 669-674.

MOSSMAN, H.W. (1987). Vertebrate fetal membranes: comparative ontogeny and morphology; evolution; phylogenetic significance; basic functions; research opportunities. London, Macmillan.

MYATT, L. and CUI, X. (2004). Oxidative stress in the placenta. Histochem. Cell Biol. 122: 369-382.

MYATT, L., ROSENFIELD, R.B., EIS, A.L.W., BROCKMAN, D.E., GREER, I. and LYALL, F. (1996). Nitrotyrosine residues in placenta. Evidence of peroxynitrite formation and action. Hypertension, 28: 488-493.

NAICKER, T., KHEDUN, S.M., MOODLEY, J. and PIJNENBORG, R. (2003) Quantitative analysis of trophoblast invasion in preeclampsia. Acta Obstet Gynecol. Scand. 82: 722-729.

NICOL, C.J., ZIELENSKI, J., TSUI, L.-C. and WELLS, P.G. (2000). An embryoprotective role for glucose-6-phosphate dehydrogenase in develop mental oxidative stress and chemical teratogenesis. FASEB J. 14: 111-127.

ORNOY, A. (2007). Embryonic oxidative stress as a mechanism of teratogenesis with special emphasis on diabetic embryopathy. Reprod. Toxicol. 24: 31-41.

PALMER, M.E., WATSON, A.L. and BURTON, G.J. (1997). Morphological analysis of degeneration and regeneration of syncytiotrophoblast in first trimester villi during organ culture. Hum. Reprod. 12: 379-382.

PATEL, J., MCLEOD, L.E., VRIES, R.G., FLYNN, A., WANG, X. and PROUD, C.G. (2002). Cellular stresses profoundly inhibit protein synthesis and modulate the states of phosphorylation of multiple translation factors. Eur. J. Biochem. 269 3076-85

PIJNENBORG, R., BLAND, J.M., ROBERTSON, W.B., DIXON, G. and BROSENS, I. (1981). The pattern of interstitial trophoblastic invasion of the myometrium in 
early human pregnancy. Placenta 2: 303-316.

PIJNENBORG, R., VERCRUYSSE, L. and HANSSENS, M. (2006). The Uterine Spiral Arteries In Human Pregnancy: Facts and Controversies. Placenta 27: 939-958.

PROUD, C.G. (2007). Signalling to translation: how signal transduction pathways control the protein synthetic machinery. Biochem. J. 403: 217-234.

REYNOLDS, S.R.M., FREESE, U.E., BIENIARZ, J., CALDEYRO-BARCIA, R., MENDEZ-BAUER, C. and ESCARCENA, L. (1968). Multiple simultaneous intervillous space pressures recorded in several regions of the hemochorial placenta in relation to functional anatomy of the fetal cotyledon. Am. J. Obstet. Gynecol. 102: 1128-1134.

RODESCH, F., SIMON, P., DONNER, C. and JAUNIAUX, E. (1992). Oxygen measurements in endometrial and trophoblastic tissues during early pregnancy. Obstet. Gynecol. 80: 283-285.

SALAFIA, C.M., MAAS, E., THORP, J.M., EUCKER, B., PEZZULLO, J.C. and SAVITZ, D.A. (2005). Measures of placental growth in relation to birth weight and gestational age. Am. J. Epidemiol. 162: 991-998.

SCHAAPS, J.P. and HUSTIN, J. (1988). In vivoaspect of the maternal-trophoblastic border during the first trimester of gestation. Trophoblast Res. 3: 39-48.

SEKULIC, A., HUDSON, C.C., HOMME, J.L., YIN, P., OTTERNESS, D.M., KARNITZ, L.M. and ABRAHAM, R.T. (2000). A direct linkage between the phosphoinositide 3-kinase-AKT signaling pathway and the mammalian target of rapamycin in mitogen-stimulated and transformed cells. Cancer Res. 60: 3504-3513.

SPENCER, T.E., JOHNSON, G.A., BURGHARDT, R.C. and BAZER, F.W. (2004). Progesterone and placental hormone actions on the uterus: insights from domestic animals. Biol. Reprod. 71: 2-10.

THAME, M., OSMOND, C., BENNETT, F., WILKS, R. and FORRESTER, T. (2004). Fetal growth is directly related to maternal anthropometry and placental volume. Eur. J. Clin. Nutr. 58: 894-900.

TOAL, M., CHAN, C., FALLAH, S., ALKAZALEH, F., CHADDHA, V., WINDRIM, R.C. and KINGDOM, J.C. (2007). Usefulness of a placental profile in high-risk pregnancies. Am. J. Obstet. Gynecol. 196: 363.e1-363.e7.
TSATSARIS, V., GOFFIN, F., MUNAUT, C., BRICHANT, J.F., PIGNON, M.R., NOEL, A., SCHAAPS, J.P., CABROL, D., FRANKENNE, F. and FOIDART, J.M. (2003). Overexpression of the soluble vascular endothelial growth factor receptor in preeclamptic patients: pathophysiological consequences. J. Clin. Endocrinol. Metab. 88: 5555-5563

WALTON, A. and HAMMOND, J. (1938). The maternal effects on growth and conformation in Shire horse-Shetland pony crosses. Proc. Roy. Soc. Lond. Ser. B, Biol. SCi. 125: 311-335

WATSON, A.L., PALMER, M.E., JAUNIAUX, E. and BURTON, G.J. (1997). Variations in expression of copper/zinc superoxide dismutase in villous trophoblast of the human placenta with gestational age. Placenta 18: 295-299.

WATSON, A.L., SKEPPER, J.N., JAUNIAUX, E. and BURTON, G.J. (1998). Changes in the concentration, localisation and activity of catalase within the human placenta during early gestation. Placenta 19: 27-34.

WEK, R.C., JIANG, H.Y. and ANTHONY, T.G. (2006). Coping with stress: elF2 kinases and translational control. Biochem. Soc. Trans. 34: 7-11.

YANG, Z.Z., TSCHOPP, O., BAUDRY, A., DUMMLER, B., HYNX, D. and HEMMINGS, B.A. (2004). Physiological functions of protein kinase B/Akt. Biochem. Soc. Trans. 32: 350-354.

YANG, Z.Z., TSCHOPP, O., HEMMINGS-MIESZCZAK, M., FENG, J., BRODBECK, D., PERENTES, E. and HEMMINGS, B.A. (2003). Protein kinase B alpha/Akt1 regulates placental development and fetal growth. J. Biol. Chem. 278: 3212432131.

YUNG, H.-W., CAlABRESE, S., HYNX, D., heMmings, B.A., CETIN, I. CHARNOCK-JONES, D.S. and BURTON, G.J. (2008). Evidence of placental translation inhibition and endoplasmic reticulum stress in the etiology of human intrauterine growth restriction. Am. J. Pathol. 173: 451-462.

YUNG, H.-W., KOROLCHUK, S., TOLKOVSKY, A., CHARNOCK-JONES, D.S. and BURTON, G.J. (2007). Endoplasmic reticulum stress exacerbates ischaemiareperfusion induced apoptosis through attenuation of PKB/Akt synthesis in human choriocarcinoma cells. FASEB J21: 872-884. 


\section{Further Related Reading, published previously in the Int. J. Dev. Biol.}

See our recent Special Issue Epigenetics \& Development edited by Saadi Khochbin and Stefan Nonchev at: http://www.ijdb.ehu.es/web/contents.php?vol=53\&issue=2-3

See Special Issue Pattern Formation edited by Michael K. Richardson and Cheng-Ming Chuong at: http://www.ijdb.ehu.es/web/contents.php?vol=53\&issue=5-6

Puzzles of mammalian fertilization - and beyond J. Michael Bedford Int. J. Dev. Biol. (2008) 52: 415-426

A simple in vivo approach to investigate invasive trophoblast cells Juan A. Arroyo, Toshihiro Konno, Darya C. Khalili and Michael J. Soares Int. J. Dev. Biol. (2005) 49: 977-980

Involvement of the proto-oncogene c-ets 1 and the urokinase plasminogen activator during mouse implantation and placentation.

D Grevin, J H Chen, M B Raes, D Stehelin, B Vandenbunder and X Desbiens Int. J. Dev. Biol. (1993) 37: 519-529

The human placenta becomes haemochorial at the 13th week of pregnancy. J M Foidart, J Hustin, M Dubois and J P Schaaps

Int. J. Dev. Biol. (1992) 36: 451-453

Tumor necrosis factor in the human fetoplacentary unit.

E Saksela and $M$ Jäättelä

Int. J. Dev. Biol. (1989) 33: 173-176

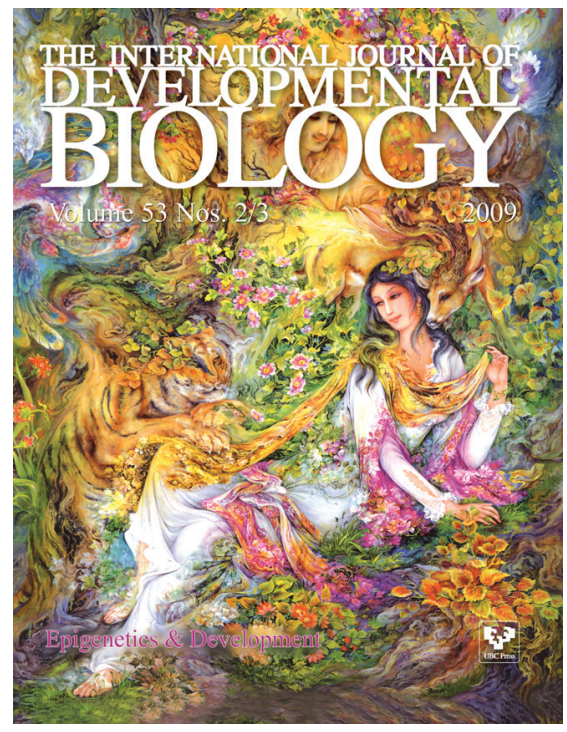

5 yr ISI Impact Factor $(2008)=3.271$
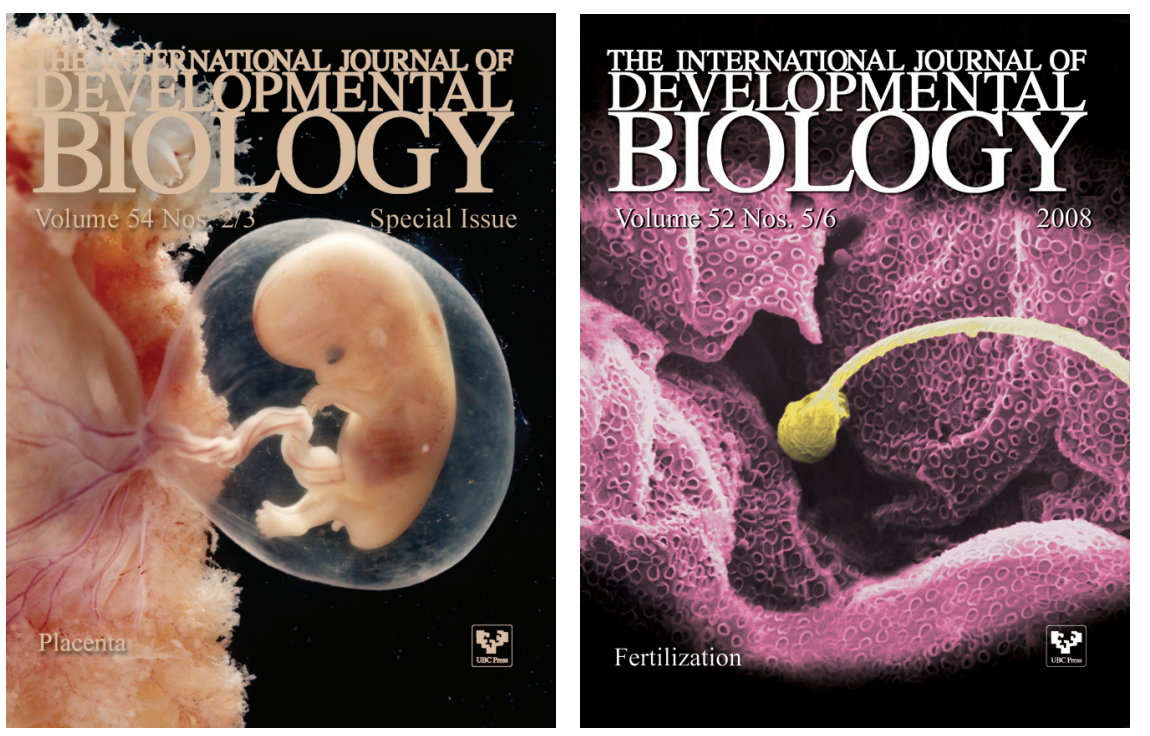